\title{
Level of Stress and Coping Strategies Adopted by Care Givers of Patients Admitted in Critical Care Units
}

\author{
Anumol KK ${ }^{1}$, Ms. Anupama Das Antony ${ }^{1}$, Binju Thomas ${ }^{1}$, Chinju Mathew ${ }^{1}$, Deepthi Mathew ${ }^{1}$, DhanyaBabu ${ }^{1}$ and $^{2}$ \\ Syed Imran ${ }^{2 *}$
}

${ }^{1}$ Nursing student, Yenepoya University, India

${ }^{2}$ Department of Mental Health Nursing, Yenepoya University, India

Submission: December 28, 2018; Published: January 30, 2019

*Corresponding author: Syed Imran, Nursing student, Yenepoya University, Mangalore, Karnataka, India

\begin{abstract}
Background: Stress is a part of our lives. We live with it; deal with it, and above all worry about it. Coping strategies refers to the specific efforts, both behavioral and psychological that people employ to master, tolerate, reduce, or minimize stressful events. A care giver is the person belonging to the patient's informal support systems who takes care and who commits most of his or her time to that task without receiving any economical revenge.
\end{abstract}

Objectives: To determine the level of stress among care givers of patient admitted in critical care units.

a) To determine the level of coping strategies adopted by the caregivers of patient admitted in critical care units.

b) To find the relationship between the level of stress and coping strategies adopted by the care givers of patients admitted in critical care units.

c) To find the association between level of stress and selected demographic variables.

d) To find the association between level of coping strategies and selected demographic variables.

Methods: A descriptive study design was adopted in order to assess the level of stress and coping strategies adopted by caregivers of patients admitted in critical care units in a selected hospital at Mangalore. The tool used for the study was DASS-21 stress scale and Brief COPE scale. The content validity of the tool was established in consultation with seven experts in the field of Mental Health Nursing, Psychiatric Medicine, Psychology, Medical surgical Nursing, Child Health Nursing, Community Health Nursing, obstetrics and Gynecology. Reliability of the tool was tested by Crohnbach's' alpha method. The sampling technique adopted was non-probability convenient sampling. The sample size was 100. Pilot study was conducted to find out the feasibility of the study. Data collected from the samples were analyzed using descriptive and inferential statistics.

Result: The study results revealed that majority of the caregivers (39\%) 0 were in the age group 31-40 years. Among them $52 \%$ were males and $48 \%$ were Muslims. Majorities (45\%) of the caregivers were living in semi urban area and $50 \%$ of them belonged to nuclear family. Majority $(43 \%)$ of the caregivers having only primary school education. Most of the $(32 \%)$ caregivers were private employees. Majority (47\%) of the family had monthly income between 5001-10000. Majority (31\%) of the caregivers were siblings of the patient. Most of the (85\%) of caregivers were staying with the patient for 1-10 days. Majority of them (30\%) had moderate level of stress, $22 \%$ had mild and severe level of stress, $17 \%$ had normal level of stress and $9 \%$ had extremely severe level of stress. Majority of the caregivers (52\%) had average coping. The study also revealed that stress score and coping score were dependent of selected demographic variables

Conclusion: The findings of the study reveals that $30 \%$ of caregivers had moderate level of stress and $22 \%$ had mild stress. Stress score and coping score were not dependent on selected demographic variables.

Keywords: Stress; Coping; Caregiver; Patient; Critical conditions

\section{Introduction}

Stress is a part of our lives. We live with it; deal with it, and above all worry about it. It is a state produced by a change in the environment that is perceived as challenging, threatening or damaging to once dynamic balance or equilibrium [1,2]. Coping strategies refers to the specific efforts, both behavioral and psychological that people employ to master, tolerate, reduce, or minimize stressful events. Coping consists of the cognitive and behavioral efforts are made to manage an anxious situation $[3,4]$. A care giver is the person belonging to the patient's informal support systems who takes care and who commits most of his or her time to that task without receiving any economical revenge. Family members are the most important physical and emotional 
care providers to the patient in critical care units [5,6]. Admission in critical care unit generates a stressful situation for both the patient and family members. Patients with terminal or acute illness are requiring intensive and immediate care.

The ICU provides treatment for adults and children with conditions, such as disturbed consciousness or coma, acute respiratory failure or acute exacerbation of chronic respiratory failure, shock, acute drug intoxication, serious metabolic disorder (e.g. hepatic or renal dysfunction, diabetic ketoacidosis or environmental disorder), multiple trauma, post resuscitation encephalopathy and severe sepsis [7]. Intensive care admission can be a stressful event for the families of critically ill patients [8].

\section{Materials and Methods}

A descriptive study design was adopted in order to assess the level of stress and coping strategies adopted by caregivers

Table 1: Frequency and percentage distribution of sample characteristics. $\mathrm{N}=100$.

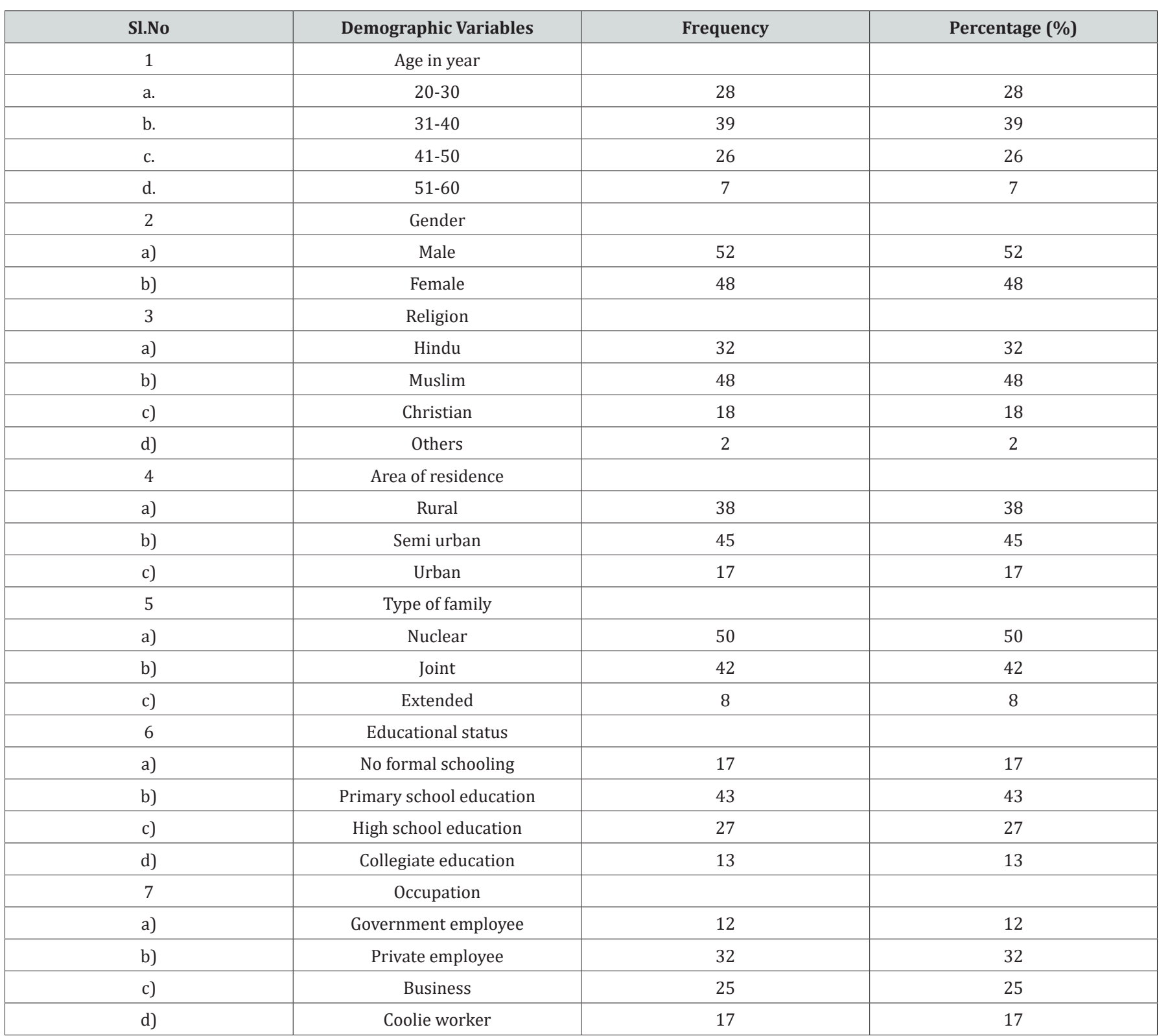

of patients admitted in critical care units in a selected hospital at Mangalore. The tool used for the study was DASS-21 stress scale and Brief COPE scale. The content validity of the tool was established in consultation with seven experts in the field of Mental Health Nursing, Psychiatric Medicine, Psychology, Medical surgical Nursing, Child Health Nursing, Community Health Nursing, obstetrics and Gynecology [9]. Reliability of the tool was tested by Crohnbach's'alpha method. The sampling technique adopted was non-probability convenient sampling. The sample size was 100 . Pilot study was conducted to find out the feasibility of the study. Data collected from the samples were analyzed using descriptive and inferential statistics.

\section{Result and Discussion}

(Table 1) Section 1: Description of subjects according to the level of stress. 
JOJ Nursing \& Health Care

\begin{tabular}{|c|c|c|c|}
\hline e) & Others & 14 & 14 \\
\hline 8 & Monthly income of family in rupees & & \\
\hline a) & Below 5000 & 12 & 12 \\
\hline b) & $5001-10000$ & 47 & 47 \\
\hline c) & $10001-15000$ & 27 & 27 \\
\hline d) & $15001-20000$ & 11 & 11 \\
\hline e) & $\geq 20001$ & 3 & 3 \\
\hline 9 & Relationship with patient: & & \\
\hline a. & Parents & 17 & 17 \\
\hline b. & Son or daughter & 27 & 27 \\
\hline c. & Husband or wife & 15 & 15 \\
\hline d. & Siblings & 31 & 31 \\
\hline e. & Others & 10 & 10 \\
\hline 10 & Duration of stay with patient & & \\
\hline a. & 10-Jan & 85 & 85 \\
\hline b. & 20-Nov & 12 & 12 \\
\hline c. & $21-30$ & 3 & 3 \\
\hline
\end{tabular}

This section deals with the analysis and interpretation of data with regard to the stress Level of caregivers of patient admitted in critical care units obtained through the stress rating scale. (Table 2) shows that only $9 \%$ of caregivers have extremely severe stress and $22 \%$ of caregivers have severe stress and $30 \%$ of caregivers have moderate stress and $22 \%$ caregivers have mild stress and remaining $17 \%$ have no stress.

Table 2: Description of subjects according to the level of stress.

\begin{tabular}{|c|c|c|c|}
\hline Level of Stress & Stress Score & Frequency & Percentage (\%) \\
\hline Normal & $0-14$ & 17 & $17 \%$ \\
\hline Mild & $15-18$ & 22 & $22 \%$ \\
\hline Moderate & $19-25$ & 30 & $30 \%$ \\
\hline Severe & $26-33$ & 22 & $22 \%$ \\
\hline Extremely severe & $34+$ & 9 & $9 \%$ \\
\hline
\end{tabular}

$\mathrm{N}=100$. Max score-52, minimum score- 0 .

Section 2: Description of subject according to their level of coping.

The section deals with the analysis and interpretation of data with regards to the level of coping of caregivers of patients admitted in critical care units obtained through the brief coping scale.

Table 3: Shows that only $3 \%$ caregivers have well coping and $52 \%$ have average coping and $45 \%$ have poor coping. Max score- 112 , minimum score-28.

\begin{tabular}{|c|c|c|c|}
\hline Category & Score & Frequency & Percentage (\%) \\
\hline Poor coping & $28-56$ & 45 & $45 \%$ \\
\hline Average coping & $57-84$ & 52 & $52 \%$ \\
\hline Well coping & $85-112$ & 3 & $3 \%$ \\
\hline
\end{tabular}

Data is presented in the form of (Table 3) and diagram. (Table 3 ) shows that only $3 \%$ caregivers have well coping and $52 \%$ have average coping and $45 \%$ have poor coping.

\section{Discussion}

This chapter presents the major findings of the study and discusses them in relation to similar studies conducted by the researchers. The study intends to assess the level of stress and coping strategies adopted by caregivers of patients admitted in critical care units in a selected Hospital at Mangalore [10]. The findings of the study have been discussed with reference to objectives and hypothesis along with findings of other studies. The findings of the study are discussed under the following headings.

Description of level of stress and coping strategies adopted by caregivers of patients admitted in critical care units

Description of level of stress among caregivers of patients admitted in critical care units. In the present study result revealed that most of the caregivers (39\%) belongs to the age group of 31-40 years. Majority of care givers (52\%) are males. Most of the caregivers $48 \%$ belongs to Muslim religion highest percentage of the caregivers (45\%) staying in semi urban area majority of the care givers (50\%) are from nuclear family, most of the caregivers (32\%) are private employee, most of the caregivers (47\%) have monthly income between 5001-10000, highest percentage (31\%) of caregivers are siblings of the patients, majority of the caregivers (85\%) are staying with the patient since 1-10 days. The study showed that $9 \%$ of caregivers have extremely severe stress and $22 \%$ of caregivers have severe stress and $30 \%$ of caregivers have moderate stress and $22 \%$ caregivers have mild stress and remaining $17 \%$ have no stress. Majority of the caregivers (52\%) have average coping and (45\%) have poor coping and only (3\%) caregivers have well coping [11-15].

Similar findings were also found in a descriptive study was conducted in Dharwad to assess the level of stress and coping mechanism among family members of clients admitted in critical care unit. The study revealed that a majority of $54(90 \%)$ members 
were moderately stressed and $1(1.66 \%)$ were mild stress and 5 $(8.3 \%)$ severely stressed [16-20]. The way of coping experienced by family members were $50(83.3 \%)$ were able to cope some extent, $0(00 \%)$ were able to cope effectively and 10 (16.6\%) were not able to cope.

\section{Association between level of stress and selected demographic variables}

The present study findings show that there is no significant association between stress scores and selected demographic variables.

\section{Association between levels of coping with selected demographic variables}

The present study findings show that there is no significant association between coping scores and selected demographic variables.

\section{Conclusion}

This chapter includes the major findings of the study, nursing implications, limitations, suggestions and recommendations. The following conclusions are drawn on the bases of findings of the study.

a) Majority of caregivers (67\%) in this study are in the age group of $20-40$ years and $33 \%$ are in the age group of $41-60$ years.

b) Majority of care givers (52\%) included in this study are males and $48 \%$ are females.

c) Highest percentages of caregivers (48\%) belongs to Muslim, 32\% care givers are belonging to Hindu religion, $18 \%$ are belongs to Christian religion, only $2 \%$ of caregivers are belongs to other religion.

d) Majority of caregivers (45\%) are staying in semi-urban area, $38 \%$ of caregivers staying in rural and $17 \%$ are staying in urban area.

e) Most of the caregivers (50\%) are from nuclear family, $42 \%$ caregivers are belonging to joint family and $8 \%$ from extended family.

f) Majority of caregivers (43\%) are having primary school education, $27 \%$ of have high school education, $17 \%$ of caregivers had no formal education and only $13 \%$ of them have college education.

g) Majority of caregivers (32\%) are private employee, $25 \%$ of them are doing business, $17 \%$ are coolie worker, $14 \%$ of them are other workers and $12 \%$ are Government employees.

h) Majority of caregivers (47\%) have income between $5001-10000,27 \%$ of them have income between $10001-$ $20000,12 \%$ of them have income between less than 5000 ,11\% have income between $15001-20000,3 \%$ of care givers have income more than 20001. i) Most of the caregivers (31\%) are siblings of the patient, $27 \%$ of caregivers are son or daughters, $17 \%$ of caregivers are parents, $15 \%$ of caregivers are husband or wife and only $10 \%$ of caregivers are include in the others category.

j) Majority of caregivers (85\%) are staying with the patient since 1 - 10 days, $12 \%$ of care givers are 11 - 20 days, and only $3 \%$ of caregivers are staying with the patient for one month.

\section{Acknowledgments}

The authors express sincere thanks to the faculty of Yenepoya Nursing College Mangalore and the study participants for their whole-hearted support.

\section{References}

1. Hinkle JL, Cheever KH (2000) Brunner and Suddarth's textbook of medical-surgical nursing. Wolters Kluwer Publications, Philadelphia, USA.

2. Vati J (2001) Textbook of nursing foundation-concepts and perspectives. Jaypee Health Science Publications, USA, pp. 175-177.

3. Mc Arthur JD, Mac CT (1998) Journal of Research Network of Socio-economic Status \& Health (1): 1-4.

4. Acaroglu R, Kaya H (2006) A descriptive study to assess the levels of anxiety and ways of coping of family members of patients hospitalized in neurosurgery ICU. Turkey (20): 2300.

5. Clark RE, Drake (1994) Expenditures of time and money by families of people with severe mental illness and substance use disorders. Community Mental Health Journal 30(2): 145-63.

6. Shorofi SA, Jannati Y, Moghaettam HR, Yazdani Charati J (2016) Psychosocial needs of families of intensive care: Perceptions of nurses and families. Niger Med J 57(1): 10-18.

7. Matsuda, Naoyuki (2011) Emergency and medical intensive care unit. Nagoya University Hospital (12): 752-741.

8. Pillai L, Aigalikar S, Vishwasrao SM, Husainy SM (2010) Can we predict intensive care relatives at risk for posttraumatic stress disorder? Indian Journal of Critical Care Medicine 14(2): 83-87.

9. Chartier L, Coutu W (2005) Families in Intensive care unit, their needs and anxiety level. Intensive Care Nurse 5(1): 11-18.

10. Smith SE, Brownwyn HL (2017) What is an Intensive care unit? (17): 9-11.

11. Hwang DY (2014) Journal of Critical Care (2): 29.

12. Kulkarni HS, Mallapalli A, Parker SR, Kainad DR, Guntapalli K (2011) Psychological impact of an ICU admission on relatives of patients in American and Indian hospital. Indian Journal of Critical Care Medicine 15(4): 147-56.

13. Miyauki HK, Kiyoko K (2015) Acute stress symptoms in families of patients admitted to the intensive care unit during the first 24 hours following admission in Japan. Open Journal of Nursing (5): 325-335.

14. Sangeeta P, Jyoti AS, Kapurkar KS, Sandhya J (2015) A descriptive study to assess level of stress and copying strategies seen among parents of neonates. International Journal of Science and Research 4(1):127-131.

15. Renier B, Prasanth YM (2016) Psychological and socioeconomic burden families, patients admitted in intensive care unit. International Journal of Biomedical Research 7(10): 733-737.

16. Clement A (2011) Sociology of nursing practice. Frontline Publications, India. 
17. Chui WY, Chan SW (2007) Stress and coping of Hong Kong Chinese family members during a critical illness. J Clin Nurs 16(2): 372-381.

18. Mc Adam JL, Puntillo K (2009) Symptoms experienced by family members of patients in intensive care units. Am J Crit care 18(3): 200-209.

19. Sangeeta Patil, JyothiA (2013) A Descriptive Study to Assess the Level of Stress and Copying Strategies among the Relatives of Client Admit- ted in Medical Intensive Care Unit and Surgical Intensive Care Unit in Krishna Hospital, Karad. International Journal of Science and Research 4(1):127-131.

20. Jyotsna Maruti W, Samuel Fernandis (2017) Assessment of stress and coping strategies among spouses of patients admitted in intensive care unit at selected hospitals. Sinhgad College of Nursing 1(7): 55-57.

\section{Your next submission with Juniper Publishers will reach you the below assets}

- Quality Editorial service

- Swift Peer Review

- Reprints availability

- E-prints Service

- Manuscript Podcast for convenient understanding

- Global attainment for your research

- Manuscript accessibility in different formats

(Pdf, E-pub, Full Text, Audio)

- Unceasing customer service

Track the below URL for one-step submission https://juniperpublishers.com/online-submission.php 